\title{
Fabrication and Growing Kinetics of Highly Dispersed Gadolinium Zirconate Nanoparticles
}

\author{
Renbo Zhu ${ }^{1}$, Jianpeng Zou ${ }^{2}$, Jie Mao ${ }^{3 *}$, Xiaofeng Zhang ${ }^{3}$, Chunming Deng ${ }^{3}$, Min Liu ${ }^{3}$, Wenlong Chen ${ }^{4}$ \\ ${ }^{1}$ School of Materials Science and Engineering, University of New South Wales, Sydney, Australia \\ ${ }^{2}$ State Key Laboratory of Powder Metallurgy, Central South University, Changsha, China \\ ${ }^{3}$ National Engineering Laboratory for Modern Materials Surface Engineering Technology \& the Key Lab of Guangdong for Modern Surface Engi- \\ neering Technology, Guangdong Institute of New Materials, Guangzhou, China \\ ${ }^{4}$ Guangdong Industrial Analysis and Testing Center, Guangzhou, China
}

*Corresponding Author: Jie Mao, Changxing Road No. 363, Tianhe District, Guangzhou, 510650, China, maojie@gdinm.com

\begin{abstract}
:
Highly dispersed gadolinium zirconate (GZ) nanoparticles with fluorite structure were successfully synthesized by co-precipitation method, and their phase composition and microstructure, formation mechanism, and grain growth kinetics were investigated. The results suggest that the nanoparticles were obtained through hydroxide dehydration and solid phase reaction. High dispersion was accomplished by ethanol solvent to reduce the hydrogen bond and sodium dodecyl benzene sulfonate (SDBS) surfactant to increase the electrostatic repulsion between the nanoparticles. The grain growth activation energy of GZ powders calcined at lower temperature $\left(<120{ }^{\circ} \mathrm{C}\right)$ is $86.5 \mathrm{~kJ} / \mathrm{mol}\left(Q_{l}\right)$, and the grain growth activation energy of GZ powders calcined at higher temperature $\left(>1200^{\circ} \mathrm{C}\right)$ is $148.4 \mathrm{~kJ} / \mathrm{mol}\left(Q_{h}\right)$. The current study shows that the optimal process to synthesize dispersed GZ nanoparticles includes ethanol solvent, $3 \mathrm{wt} . \% \mathrm{SDBS}$ surfactant, and $1100{ }^{\circ} \mathrm{C}$ as calcining temperature.

Keywords: Gadolinium zirconate; Co-precipitation method; Phase structure; Kinetics; Dispersed nanoparticles

Citation: R.B. Zhu et al., Fabrication and Growing Kinetics of Highly Dispersed Gadolinium Zirconate Nanoparticles. Res Appl Mat Sci, 2019,1(1): 28-34. https://doi.org/10.33142/msra.vli1.670
\end{abstract}

\section{Introduction}

The rare earth zirconates, $\mathrm{Ln}_{2} \mathrm{Zr}_{2} \mathrm{O}_{7}$ ( $\mathrm{Ln}$ denotes a rare earth element) with pyrochlore and defect fluorite structure, have received considerable attention in various industrial applications, including matrix nuclear fuel ${ }^{[1-3]}$, catalytic materials ${ }^{[4-6]}$, and thermal barrier coatings (TBCs) ${ }^{[7-9]}$. These zirconates have significant advantages, which include low thermal conductivity and excellent thermal stability ${ }^{[10-13]}$. Therefore, $\mathrm{Ln}_{2} \mathrm{Zr}_{2} \mathrm{O}_{7}$ is widely used as TBCs to provide better thermal insulation and corrosion resistance for hot-section components of gas turbines.

$\mathrm{Gd}_{2} \mathrm{Zr}_{2} \mathrm{O}_{7}(\mathrm{GZ})$ is a good candidate as it shows significant superiority over traditional $\mathrm{Y}_{2} \mathrm{O}_{3}$ stabilized $\mathrm{ZrO}_{2}$ (YSZ) materials due to its low sintering rate, low thermal conductivity and high thermal stability ${ }^{[14-16]}$. Besides, GZ presents the relatively higher coefficient of thermal expansion (CTE) among the rare earth zirconates ${ }^{[17]}$, which contributes to the relatively lower thermal stress in the interface of ceramic layer and bond layer and longer service life. Well dispersed nanoparticles increase material reac- tivity, which assists TBC preparation, such as powder evaporation in the plasma plume and columnar coating formation with better fracture resistance.

Various methods have been proposed to obtain highly dispersed GZ nanoparticles, including solid-state reaction, solgel, combustion, hydrothermal synthesis and co-precipitation $[11,18-21]$. Solid-state reaction is the common method to synthesize zirconate nanoparticles but requires high sintering temperature (above $1450{ }^{\circ} \mathrm{C}$ ) ${ }^{[22]}$, which is not good for achieving high dispersion, since agglomeration becomes more severe at higher sintering temperatures. Composition segregation is another shortcoming in this method. It is necessary to use the expensive alkoxide in the sol-gel method, which is unsuitable for manufacturing nanoparticles. High heating and cooling rates in the combustion method cause the formation of defect concentration and non-equilibrium phase in the products. The hydrothermal method presents the high requirements for the equipments and can produce a limited amount of powders. On the other hand, the co-precipitation method can reduce synthesis temperature, 
improve production, and accurately control chemical composition. Thus, co-precipitation has a great potential for manufacturing dispersed GZ nanoparticles.

It is difficult to produce the highly dispersed nanoparticles by traditional coprecipitation method since the agglomerations and sintering still exist in this process. The agglomeration includes soft agglomeration and hard agglomeration ${ }^{[23]}$. Soft agglomeration arises mainly from Van der Waals attraction, which can be destroyed easily and is beneficial to obtain dispersed particles. Hard agglomeration is formed with solid neck connection, which can't break easily. Water molecules can bridge neighboring precipitates in the co-precipitation process, producing hard agglomerates with solid necks and connecting neighboring particles after precipitate dehydration ${ }^{[24]}$. While, hydroxyl groups in the ethanol solvent are the terminal groups and obstruct bridge formation, which are promising in fabricating GZ nanoparticles with high dispersion.

However, few studies have considered agglomeration effects in the highly dispersed GZ nanoparticle production. This paper aims to synthesize GZ nanoparticles with less agglomeration by the modified co-precipitation method. The phase composition, microstructure, formation mechanism, and grain growth kinetics are also investigated.

\section{Materials and methods}

\subsection{Preparation}

Gadolinium nitrate and zirconium oxychloride (99.99\%, Golden Dragon Rare-Earth Co., Ltd., Fujian, China) were dissolved in ethanol and distilled water solvent, respectively. Then, the solutions were mixed at the atomic proportion of $\mathrm{Gd}: \mathrm{Zr}=1: 1$ and stirred for $30 \mathrm{~min}$ with different sodium dodecyl benzene sulfonate (SDBS) dispersants ratios. The precursor solution was added dropwise into ammonium hydroxide $(\mathrm{pH}=10)$ while continuously stirring to fabricate hydroxide precipitates. After filtration, the precipitates were continuously washed with the same corresponding solvent until $\mathrm{pH}$ of filtrate is 7 . Then, the precipitates were dried at $100{ }^{\circ} \mathrm{C}$ for $10 \mathrm{~h}$. After grinding in the zirconia balls and jars for $2 \mathrm{~h}$ (ball to precipitate mass ratio is $1: 1$ ), the dried precipitates were calcined above $900{ }^{\circ} \mathrm{C}$ for $2 \mathrm{~h}$.

\subsection{Analyses and measurements}

$\mathrm{X}$-ray diffractometry (XRD, D/max 2550PC, Japan) was used for phase analyses of GZ powders with different calcining temperature at a scan rate of $4 \% \mathrm{~min}$. The phase structure of the GZ powders was identified by Fourier-transform infrared (FTIR) spectroscopy (Spectrum-2, America). Particle morphology was analyzed with scanning electron microscopy (SEM, S-4300, Japan), transmission electron microscopy (TEM, JEM-2100F, Japan) and high-resolution transmission electron microscopy (HRTEM, JEM-2100F, Japan). GZ powders were also analyzed by the selected area electron diffraction (SAED) patterns. Thermal analysis of dried precipitates was performed in the air by thermo gravimetric and differential scanning calorimeter (TG/ DSC, STA-449-F5, Germany) from $25^{\circ} \mathrm{C}$ to $1400^{\circ} \mathrm{C}$ at a heating rate of $10{ }^{\circ} \mathrm{C} / \mathrm{min}$. The $\mathrm{GZ}$ powder specific surface areas were calculated by the Brunauer-Emmett-Teller (BET) nitrogen adsorption method.

\section{Results and discussion}

3.1. Gadolinium zirconate powder phase composition and microstructure

Figure 1 presents the XRD patterns for GZ powders precipitated in the ethanol solvent with 3 wt.\% SDBS and calcined above $900{ }^{\circ} \mathrm{C}$ for $2 \mathrm{~h}$. The samples exhibit similar XRD patterns, identified as single phase with defect fluorite structure (JCPDS No. 01-080-0471, space group Fm-3m). No distinct diffraction peaks of impurities exist. Thus, the pure substitutional solid solution has been successfully synthesized. As calcining temperature increases, diffraction peaks of GZ powders are sharper, which indicates GZ grain growth and improved crystallinity. However, there is no phase transformation from defect fluorite structure to pyrochlore structure, hence the defect fluorite structure remains relatively stable up to $1400{ }^{\circ} \mathrm{C}$.

As crystallization is fully developed by $1100^{\circ} \mathrm{C}$, it is necessary to set the calcining temperature above $1100{ }^{\circ} \mathrm{C}$ to ensure nanocrystal integrity. However, higher calcining temperature contributes greatly to nanoparticle sintering and hard agglomeration, which are not good for synthesizing highly dispersed nanoparticles. Thus, calcining temperature should be $1100^{\circ} \mathrm{C}$ to ensure both good GZ powder dispersion and crystal integrity.

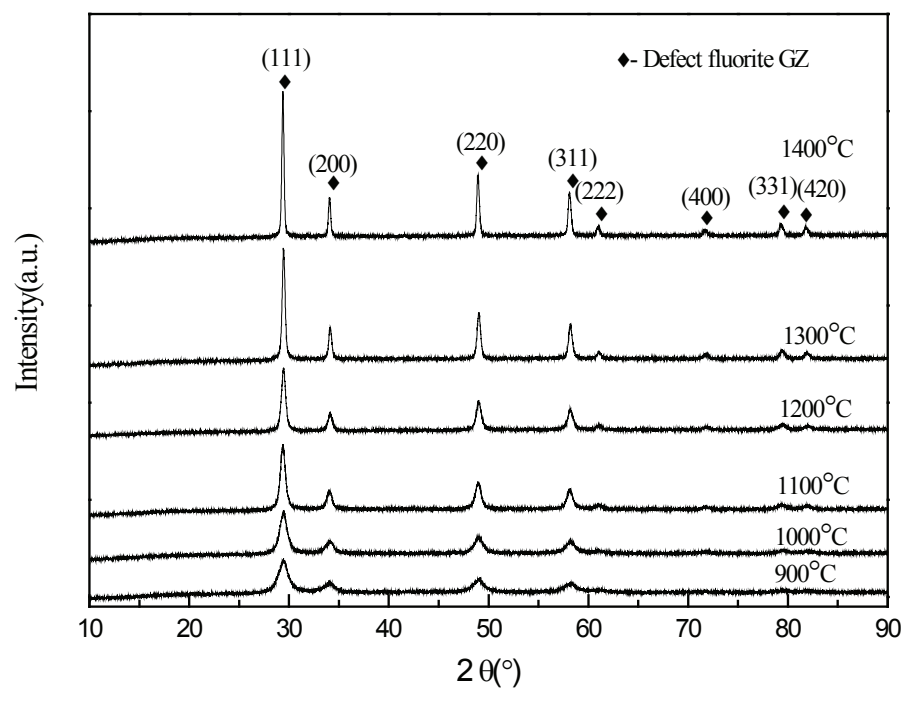

Figure 1. XRD patterns of gadolinium zirconate powders precipitated in ethanol solvent with $3 \mathrm{wt}$.\% SDBS at various calcining temperatures.

Figure 2 exhibits the infrared spectra of GZ powders at different calcining temperatures. The absorption bands centered at approximately 3446 and $1638 \mathrm{~cm}^{-1}$ are attributed to the residual water in the GZ powders, whereas bands in $1000-780 \mathrm{~cm}^{-1}$ correspond to residual nitrate vibrations. The absorption band at $610 \mathrm{~cm}^{-1}$ is shown due to $\mathrm{Zr}-\mathrm{O}$ bonds in the lattice, and the vibration frequency of $\mathrm{Gd}-\mathrm{O}$ bonds is detected at $420 \mathrm{~cm}^{-1}$. Bands at 1517,1398 and $1123 \mathrm{~cm}^{-1}$ correspond to $\mathrm{C}=\mathrm{C}, \mathrm{C}-\mathrm{N}$, and $\mathrm{C}-\mathrm{H}$ bonds in the powders calcined at $1000^{\circ} \mathrm{C}^{[25,26]}$. As calcining temperature increases to $1100^{\circ} \mathrm{C}$, these three bonds disappear, indicating loss of impurities.

Figure 3 shows SEM micrographs of GZ nanoparticles fabricated in various ways. GZ powders precipitated in water solvent (Figure 3a) exhibit no significant boundaries among GZ nanoparticles, which are severely agglomerated into larg- 
er clusters. Particle boundaries are clearly differentiated in the powders precipitated in ethanol solvent (Figure 3b), indicating better dispersion of GZ particle. BET surface areas were 23.4 and $44.5 \mathrm{~m}^{2} / \mathrm{g}$ for the powders precipitated in the water and ethanol, respectively. The larger BET surface area confirms that powders precipitated in the ethanol have better dispersion. Nanoparticles with different SDBS ratios (2, 3, and 4 wt.\%) show BET surface area $62.3,98.6$, and $85.7 \mathrm{~m}^{2} / \mathrm{g}$, respectively (Figure $3 \mathrm{c}$, Figure $3 \mathrm{~d}$, Figure $3 \mathrm{e}$ ), indicating that the amount of SDBS in dispersion follows the order: $3>4>2$ wt. $\%$. The dispersion mechanism is discussed in section 3.2.

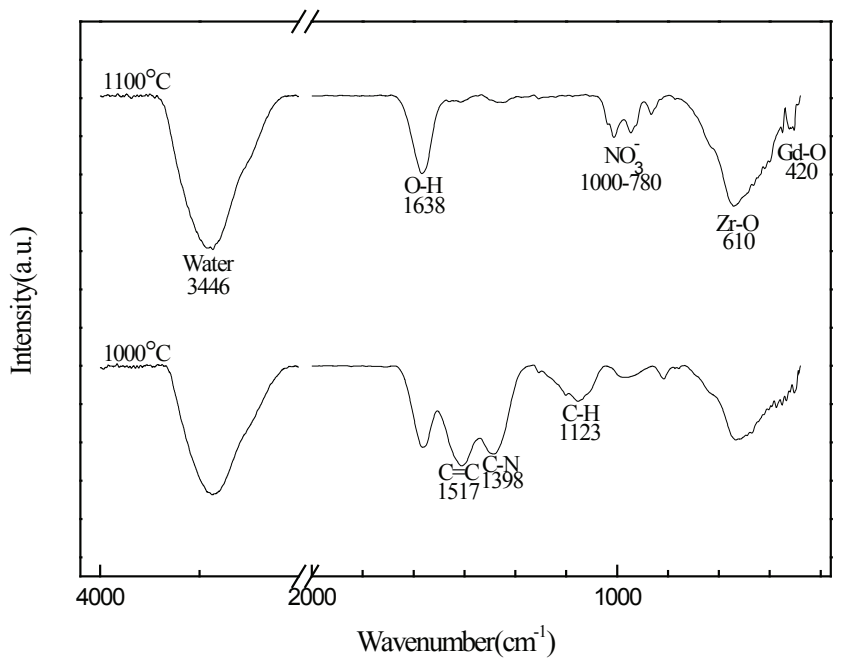

Figure 2. Infrared spectra for gadolinium zirconate powders precipitated in ethanol solvent with $3 \mathrm{wt}$ \% sodium dodecyl

benzene sulfonate at various calcining temperatures.

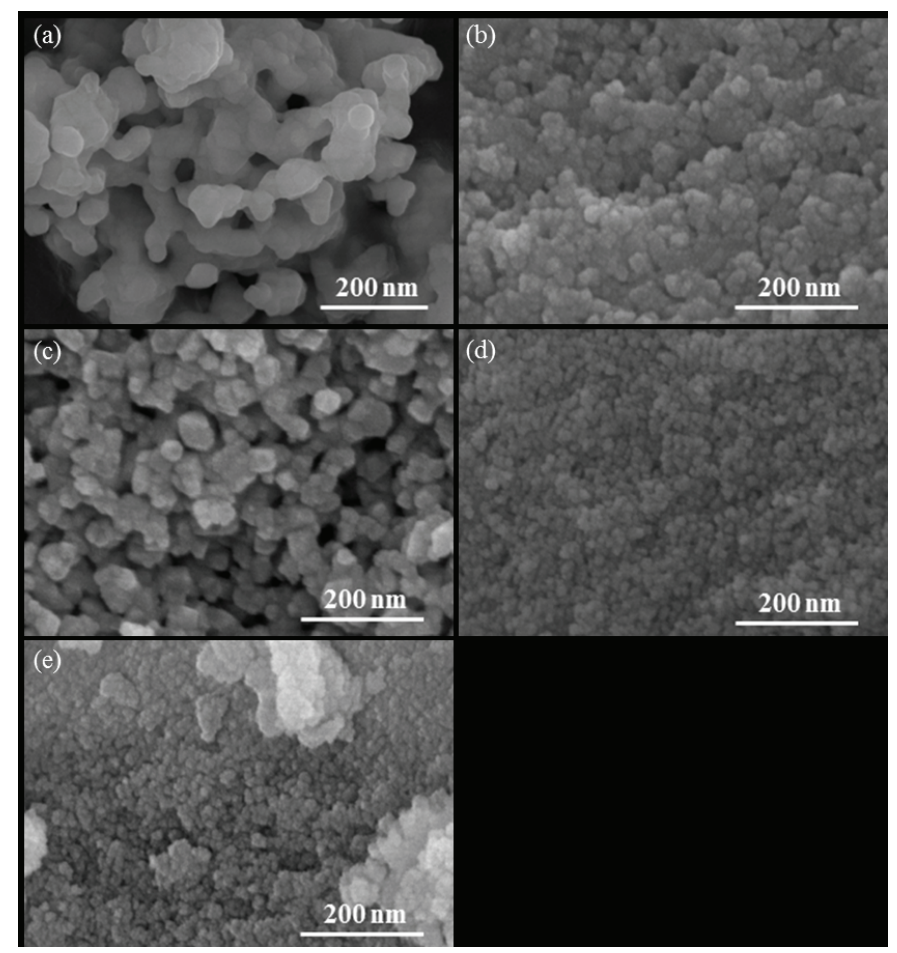

Figure 3. SEM images for gadolinium zirconate nanoparticles prepared with (a) water; (b) ethanol; and (c) 2 wt.\%, (d) 3 wt.\%, and (e) 4 wt.\% sodium dodecyl benzene sulfonate.
Figure 4 shows TEM/HRTEM images and SAED patterns for GZ powders precipitated in the water and ethanol solvent with $3 \mathrm{wt} . \%$ SDBS. GZ particle size is above $20 \mathrm{~nm}$ when precipitated in the water (Figure 4a), and GZ nanoparticles are closely agglomerated into large and dense particles. In contrast, nanoparticle size is below $20 \mathrm{~nm}$ when precipitated in the ethanol solvent with 3 wt.\% SDBS (Figure $4 \mathrm{~b}$ ). The GZ powders precipitated in the ethanol are better dispersed than the powders precipitated in the water. Figure $4 \mathrm{c}$ shows a typical HRTEM image for powders precipitated in the water, exhibiting wide lines between the grains with different orientations. It originates from Moire patterns induced by nanocrystal overlay, indicating agglomeration and sintering behavior between nanoparticles precipitated in the water. GZ powders precipitated in the ethanol exhibit clearer grain boundaries (Figure 4d), indicating better dispersion. The SAED pattern (Figure 4e) exhibits defect fluorite structure, consistent with XRD analysis, and the sharp rings indicate polycrystalline material. SAED pattern from a single grain (Figure 4f) shows diffraction spots of atomic planes, belonging to the corresponding atomic planes in the face-centered cubic structure of GZ grain.

\subsection{Gadolinium zirconate powder formation mechanism}

Hydroxide thermal analysis is conducive to clarifying hydroxide decomposition and GZ formation. Figure 5 presents the TG/ DSC analysis for dry hydroxide precipitates. The DSC curve of hydroxides shows a distinct endothermic peak at approximately $111^{\circ} \mathrm{C}$, accompanied by an abrupt weight drop ( 10\%) due to the removal of residual water in the precipitates ${ }^{[27]}$. The endothermic peak at approximately $483^{\circ} \mathrm{C}$ corresponds to zirconium hydroxide decomposition, and the peak at approximately $628^{\circ} \mathrm{C}$ corresponds to gadolinium hydroxide decomposition. No significant weight loss occurs above $628^{\circ} \mathrm{C}$, indicating that zirconia and gadolinia formation has almost completed. The exothermal peak at approximately $1065{ }^{\circ} \mathrm{C}$ corresponds to the solid phase reaction of powders, in which zirconia and gadolinia react to form GZ.

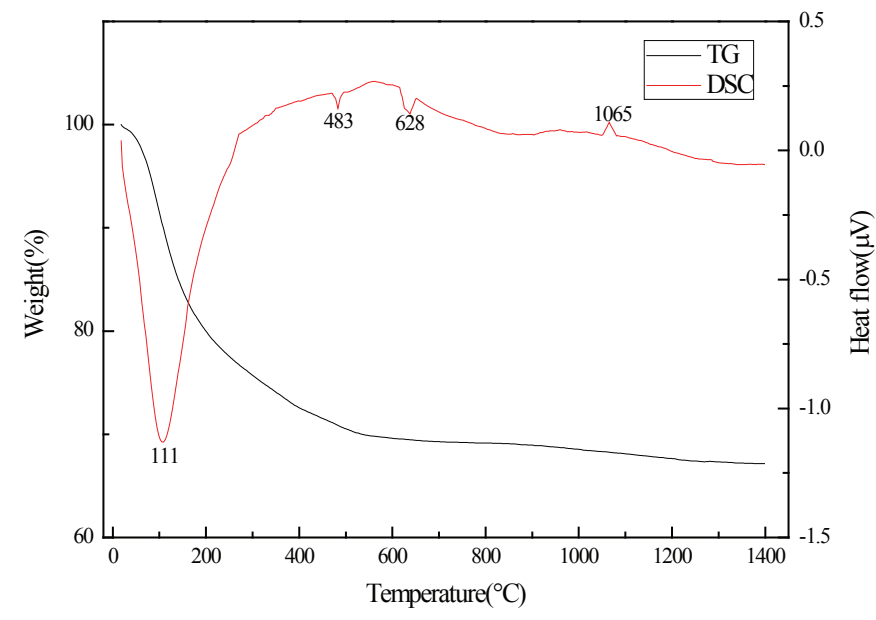

Figure 5. Thermogravimetric (TG) and differential scanning calorimeter (DSC) curves for hydroxide precipitates precipitated in ethanol solvent with $3 \mathrm{wt}$.\% sodium dodecyl benzene sulfonate 

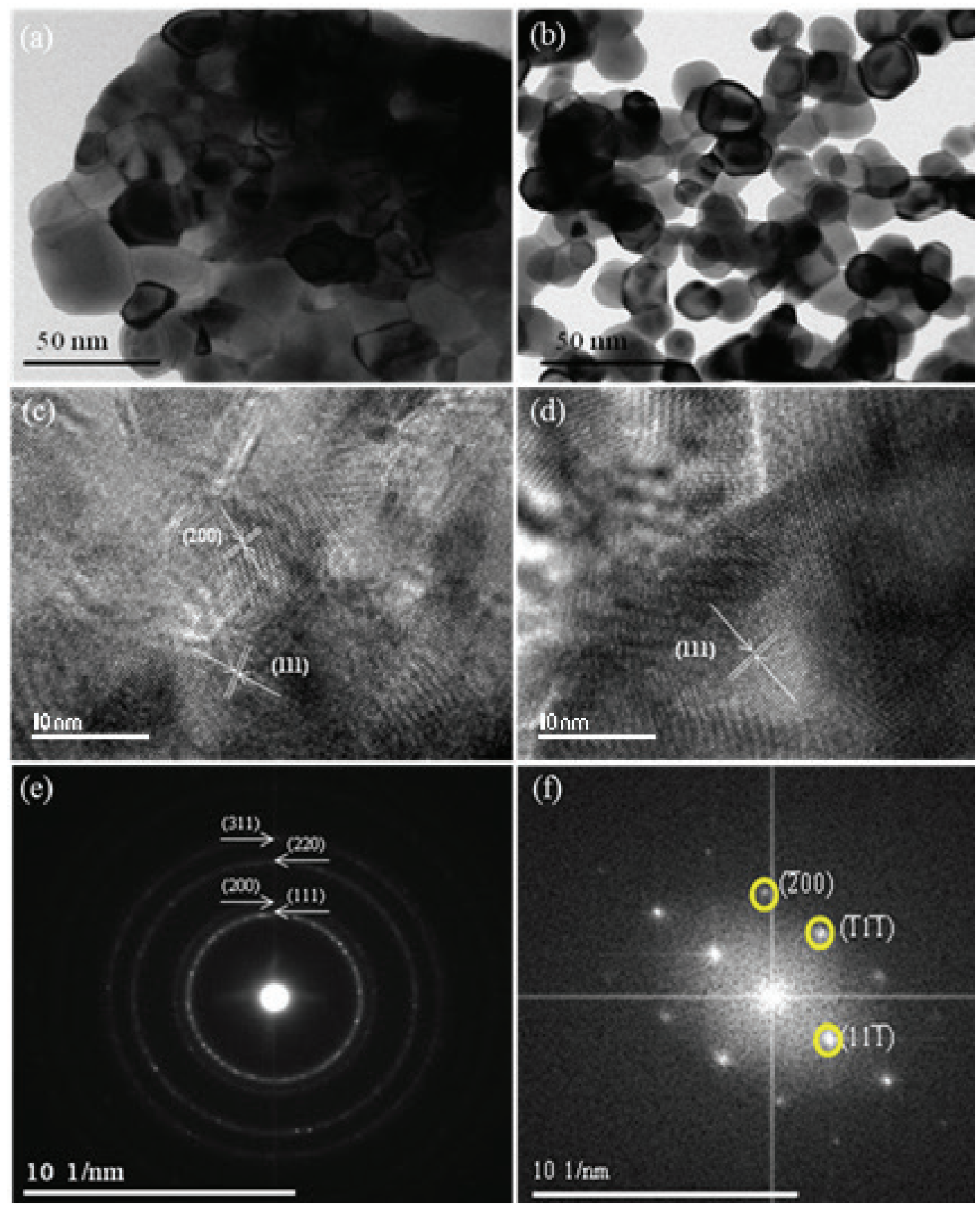

Figure 4. Morphology and crystal structure for gadolinium zirconate nanoparticle powders precipitated with 3 wt.\% SDBS. (a) TEM images, (c) HRTEM images, and (e) SAED patterns with water solvent; and (b) TEM images, (d) HRTEM images, and (f) SAED patterns with ethanol solvent.

The equations of chemical reactions in the calcining process can be expressed as

$$
\begin{aligned}
& \mathrm{Zr}(\mathrm{OH})_{4} \rightarrow \mathrm{ZrO}_{2}+2 \mathrm{H}_{2} \mathrm{O} \uparrow \quad 111^{\circ} \mathrm{C}, \\
& 2 \mathrm{Gd}(\mathrm{OH})_{3} \rightarrow \mathrm{Gd}_{2} \mathrm{O}_{3}+3 \mathrm{H}_{2} \mathrm{O} \uparrow 628^{\circ} \mathrm{C}, \\
& \quad \text { and }
\end{aligned}
$$$$
2 \mathrm{ZrO}_{2}+\mathrm{Gd}_{2} \mathrm{O}_{3} \rightarrow \mathrm{Gd}_{2} \mathrm{Zr}_{2} \mathrm{O}_{7} 1065^{\circ} \mathrm{C} \text {. }
$$

Agglomerate strength is related to the amount of hydrogen bond in the solvent, connecting the hydroxide precipitate through formation of bridges between adjacent particles. Figure
6 shows the solvent function in the model ${ }^{[28]}$. For hydroxide precipitated in the water, chemical bonds form between nanoparticles after further dehydration and sintering of precipitate, yielding hard agglomerates. However, the ethoxy group serves as the terminal group rather than bridging group, hence hydrogen bonds connecting neighboring particles don't form in the ethanol solvent and link particles together. The nonbridging hydrox$\mathrm{yl}$ groups in the ethanol solvent can obstruct bridge formation between adjacent particles and exhibit soft agglomerates. 

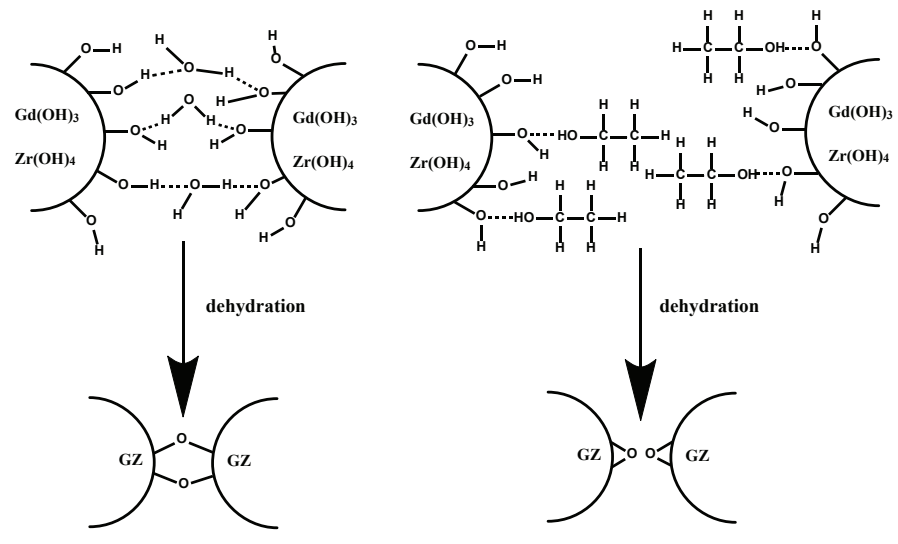

Figure 6. Agglomeration formation of GZ powders (a) hard agglomeration in the water solvent; (b) soft agglomeration in the ethanol solvent

Surfactant molecules adsorbing on the nanoparticle surfaces reduce the surface energy and reduce particle agglomeration, hence stabilizing growing particles and facilitating high dispersion. SDBS is an effective anion surfactant and can provide micelles to confine the reactions and provide electrostatic repulsion among the nanoparticles to increase their dispersion ${ }^{[29]}$, as shown in Figure 7.

The dispersion of nanoparticles improves with the SDBS concentration from 2 to 3 wt.\%, since surfactants adsorbing on the nanoparticle surfaces increase electrostatic repulsion when the total amount of surfactant is insufficient to cover all nanoparticles in the range below 3 wt.\%. However, excess surfactant increases anion concentration in the solvent and hence reduces repulsion between nanoparticles, reducing surfactant effectiveness against GZ powders agglomeration. This is because surfactants can't absorb on the nanoparticles after surfactant concentration reaches critical micelle concentration. The agglomeration among the surfactants occurs, which reduces the repulsion between nanoparticles.

\subsection{Grain growth kinetics}

We investigated grain growth kinetics to estimate GZ nanoparticle grain size. Consider the (111) lattice plane half width as an example. GZ grain sizes prepared with $3 \mathrm{wt}$ \% SDBS were estimated under different synthesis temperatures from the Scherrer equation

$G=\frac{\mathrm{k} \lambda}{B \cos \theta}$,

where $G$ is the mean grain size, $\lambda=0.15418 \mathrm{~nm}$ is the incident wavelength, $\mathrm{k}=0.89$ is the Scherrer constant, $B$ is the diffractive peak full width at half maximum (FWHM), and $\theta$ is the diffractive angle.

Figure 8 shows that the calculated GZ powder grain size with 3 wt.\% SDBS varies 7.4-36.6 nm between 900 and $1400^{\circ} \mathrm{C}$. $\mathrm{GZ}$ grain grows faster at the temperatures above $1200^{\circ} \mathrm{C}$ since more lattice disorders and defects remain when calcining temperature is below $1200{ }^{\circ} \mathrm{C}$. However, the GZ grain grows with fewer obstacles as lattice disorders decrease with the elevated temperature when calcining temperature is above $1200^{\circ} \mathrm{C}$. Well dispersed nanoparticles can increase material reactivity, which is good for TBC preparation, such as powder evaporation in the plasma plume and columnar structure formation with better fracture resistance.

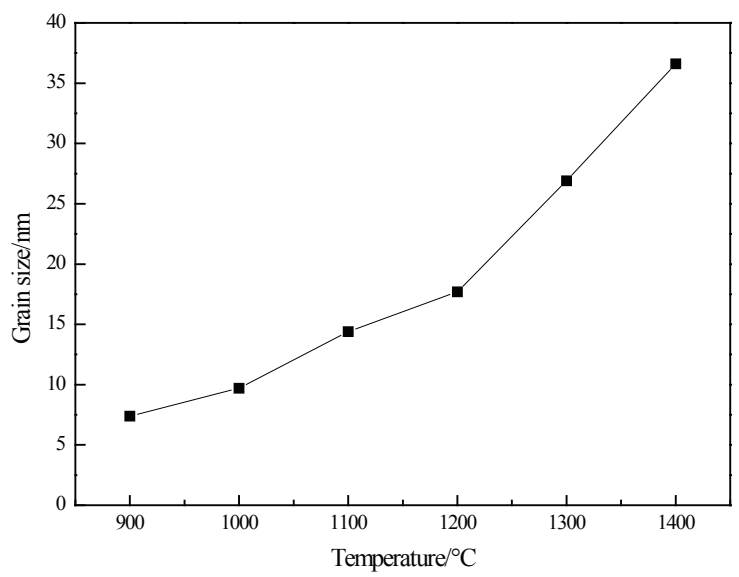

Figure 8. Grain size for gadolinium zirconate powder precipitated in ethanol solvent with $3 \mathrm{wt}$ \% sodium dodecyl benzene sulfonate at different calcining temperatures.

Classically ${ }^{[30-32]}$, grain growth rate and grain size are given as follows:

$\frac{d G(t)}{d t}=\frac{c}{G(t)}$,

where $c$ is the constant related to the temperature, $G$ and $t$

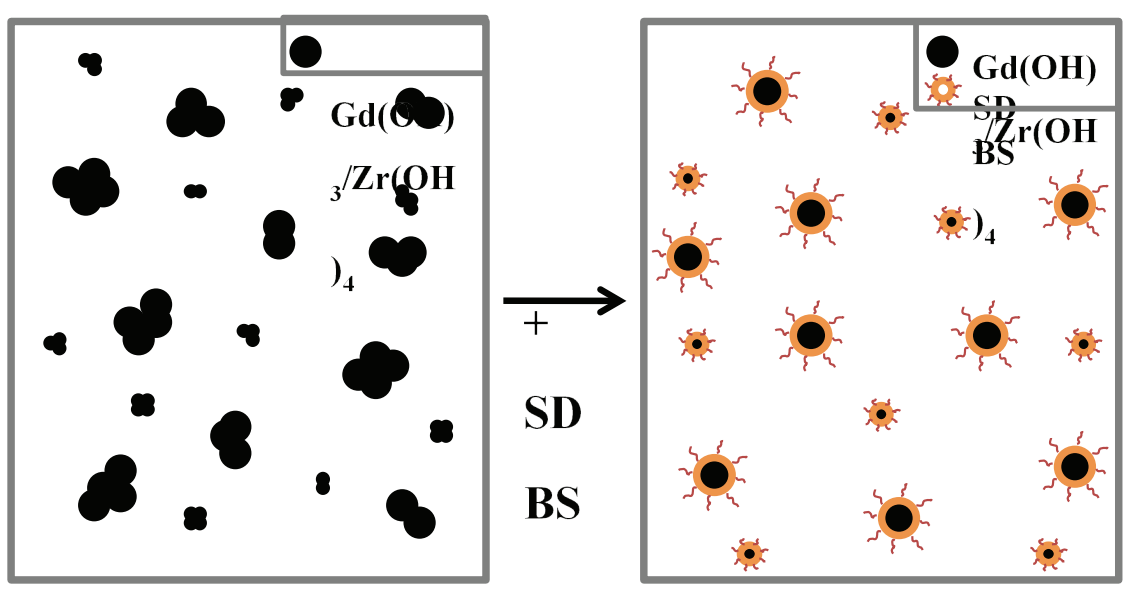

Figure 7. Dispersion mechanism model for sodium dodecyl benzene sulfonate (SDBS) on gadolinium zirconate (GZ) nanoparticles. 
are the grain size and grain growth time, respectively, $c=\frac{\mathrm{A}}{T} \exp \left(-\frac{\mathrm{Q}}{\mathrm{R} T}\right)$,

where $T$ and $\mathrm{R}$ are the calcining temperature and gas constant, respectively; A and B are the temperature-irrelevant constants; and $Q$ is the activation energy of grain growth. Then, grain growth is given as follows:

$G(t)^{2}-G_{o}^{2}=2 c t$.

In this paper, $G_{0} \approx 0$ and $t=2 \mathrm{~h}$. Thus, equation (7) is deduced as

$\ln G=\mathrm{B}-\frac{\mathrm{Q}}{2 \mathrm{R} T}$.

Figure 9 confirms that $\ln G$ is linear with respect to $1 / T$, and grain growth activation energy is deduced from the slope $(\mathrm{Q} / 2 \mathrm{R})$. The result shows grain growth activation energy of GZ powders is $86.5 \mathrm{~kJ} / \mathrm{mol}\left(Q_{l}\right)$ for the powders calcined at the lower temperature $\left(<1200{ }^{\circ} \mathrm{C}\right)$, which is less than $148.4 \mathrm{~kJ} / \mathrm{mol}\left(Q_{h}\right)$ for the powders calcined at higher temperature $\left(>1200{ }^{\circ} \mathrm{C}\right)$. At the lower temperature, GZ nanoparticles exhibit relatively smaller grain size and higher surface energy, indicating that GZ grains grow more easily with lower grain growth activation energy. Since crystallization is not fully developed, more disorders and defects are present, which lead to lower resistance of grain growth and lower grain growth activation energy at the lower calcining temperature. However, disorders and defects decrease when calcining temperature is above $1200{ }^{\circ} \mathrm{C}$ since crystallization has fully developed with relatively stable crystal structure, contributing to higher grain growth activation energy of GZ powders.

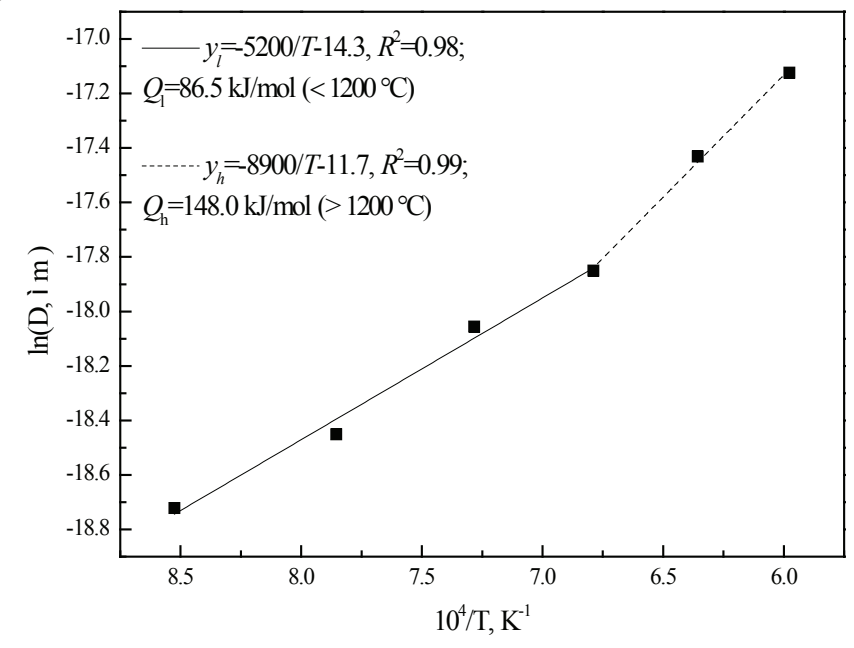

Figure 9. The relationship between $\ln \mathrm{D}$ and $1 / \mathrm{T}$ for gadolinium zirconate.

Grain growth activation energy of GZ powders is greater than that of YSZ nanoparticles $(13 \mathrm{~kJ} / \mathrm{mol}){ }^{[33]}$, supporting the stable GZ thermal properties and better sintering resistance. More pores can be retained in TBC ceramic layers, with better sintering resistance during thermal cycles. The retained pores will help relieve thermal stress concentration of ceramic layer in the thermal cycling and hence improve thermal cycling lifetime. In contrast, the amount of pores in the ceramic layer decreases with lower sintering resistance, decreasing CTE and increasing thermal mismatch in the interface of ceramic layer and underly- ing alloy. Thus, GZ application with greater sintering resistance will improve service life during thermal cycling.

\section{Conclusions}

This study successfully prepared gadolinium zirconate nanoparticles with defect fluorite structure by co-precipitation. As the calcining temperature increases from $900{ }^{\circ} \mathrm{C}$ to $1400{ }^{\circ} \mathrm{C}$, the diffraction peak of the GZ powders in XRD patterns is sharper, which indicates the grain growth from $7.4 \mathrm{~nm}$ to $36.6 \mathrm{~nm}$ between $900{ }^{\circ} \mathrm{C}$ and $1400{ }^{\circ} \mathrm{C}$ for the nanoparticles with 3 wt. $\%$ SDBS. $1100{ }^{\circ} \mathrm{C}$ is the most appropriate calcining temperature to produce highly dispersed GZ nanoparticles.

Formation of GZ nanoparticles includes dehydration of zirconium hydroxide at approximately $483{ }^{\circ} \mathrm{C}$, dehydration of gadolinium hydroxide at approximately $628^{\circ} \mathrm{C}$, and solid phase reaction at approximately $1065^{\circ} \mathrm{C}$. GZ nanoparticle dispersion can be readily accomplished by using ethanol and SDBS surfactant as reacting media. Ethanol efficiently obstructs the formation of hydrogen bond between hydroxide precipitates. SDBS surfactant further increases GZ nanoparticles dispersion, reaching optimal condition for 3 wt. $\%$ SDBS.

Grain growth activation energy for GZ nanoparticles precipitated with 3 wt. $\%$ SDBS is calculated to be $Q_{l}=86.5 \mathrm{~kJ} / \mathrm{mol}$ for GZ powders at the lower calcining temperature $(<1200$ ${ }^{\circ} \mathrm{C}$ ), which is less than $Q_{h}=148.4 \mathrm{~kJ} / \mathrm{mol}$ for GZ powders at the higher calcining temperature $\left(>1200{ }^{\circ} \mathrm{C}\right)$, due to the decreased disorders and defects in the lattice and better developed crystallization at the higher calcining temperatures. Grain growth activation energy of GZ nanoparticles is greater than that of YSZ nanoparticles, indicating that GZ nanoparticles with 3 wt.\% SDBS exhibit better sintering resistance and will be superior for preparing TBCs with longer service life.

Acknowledgements: This study was supported by the National Key Research and Development Program of China (grant 2017YFB0306100), the Natural Science Foundation of Hunan Province (grant 2018JJ2524), and the International scientific technological cooperation projects of China (grants 2015DFR50580 and 2013DFA31440).

\section{References}

[1] A Imaura, N Touran, RC Ewing. MgO-pyrochlore composite as an inert matrix fuel: Neutronic and thermal characteristics. Journal of Nuclear Materials 2009: 389: 341350.

[2] J Zhang, J Lian, F Zhang, et al. Intrinsic structural disorder and radiation response of nanocrystalline $\mathrm{Gd}_{2}(-$ $\left.\mathrm{Ti}_{0.65} \mathrm{Zr}_{0.35}\right)_{2} \mathrm{O}_{7}$ pyrochlore. Journal of Physical Chemistry C 2010; 114: 11810-11818.

[3] J Lian, KB Helean, BJ Kennedy, et al. Effect of structure and thermodynamic stability on the response of lanthanide stannate pyrochlores to ion beam irradiation. Journal of Physical Chemistry B 2006; 110: 2343-2351.

[4] LG Tejuca, JLG Fierro, JMD Tascón. Structure and reactivity of perovskite-type oxides. Advances in Catalysis 1989; 36: 237-328.

[5] N Yamazoe, Y Teraoka. Oxidation catalysis of perovskites---relationships to bulk structure and composition (valency, defect, etc.). Catalysis Today 1990; 8: 175-199. 
[6] Y Teraoka, K Torigoshi, H Yamaguchi, et al. Direct decomposition of nitric oxide over stannate pyrochlore oxides: relationship between solid-state chemistry and catalytic activity. Journal of Molecular Catalysis A: Chemical 2000; 155: 73-80.

[7] W Pan, SR Phillpot, C Wan, et al. Low thermal conductivity oxides. MRS Bulletin 2012; 37: 917-922.

[8] PK Schelling, SR Phillpot, RW Grimes. Optimum pyrochlore compositions for low thermal conductivity. Philosophical Magazine Letters 2004; 84: 127-137.

[9] XQ Cao, R Vassen, W Jungen, et al. Thermal stability of lanthanum zirconate plasma-sprayed coating. Journal of the American Ceramic Society 2001; 84: 2086-2090.

[10] L Wang, Y Wang, XG Sun, et al. Preparation and characterization of nanostructured $\mathrm{La}_{2} \mathrm{Zr}_{2} \mathrm{O}_{7}$ feedstock used for plasma spraying. Powder Technology 2011; 212: 267-277.

[11] HY Jin, D Huang, Q Gao, et al. Synthesis of lanthanum zirconium oxide nanomaterials through composite-hydroxide-mediated approach. Materials Research Bulletin 2012; 47: 51-53.

[12] X Cao, R Vassen, W Jungen, et al. Thermal stability of lanthanum zirconate plasma-sprayed coating. Journal of the American Ceramic Society 2001; 84: 2086-2090.

[13] L Ling, X Qiang, F Wang, et al. Thermophysical properties of complex rare-earth zirconate ceramic for thermal barrier coatings. Journal of the American Ceramic Society 2010; 91: 2398-2401.

[14] ZG Liu, JH Ouyang, Y Zhou, et al. Structure and thermal conductivity of $\mathrm{Gd}_{2}\left(\operatorname{TixZr}_{1-\mathrm{x}}\right)_{2} \mathrm{O}_{7}$ ceramics. Materials Letters 2008; 62: 4455-4457.

[15] L Ling, X Qiang, F Wang, et al. Thermophysical properties of complex rare-earth zirconate ceramic for thermal barrier coatings. Journal of the American Ceramic Society 2010; 91: 2398-2401.

[16] HM Zhou, DQ Yi, H Zhong. Dy and Ce co-doped $\mathrm{La}_{2} \mathrm{Zr}_{2} \mathrm{O}_{7}$ ceramic powder used for thermal barrier coating. Journal of Inorganic Materials 2008; 23: 567-572.

[17] R Vassen, MO Jarligo, T Steinke, et al. Overview on advanced thermal barrier coatings, Surface and Coatings Technology 2010; 205: 938-942.

[18] MOD Jarligo, YS Kang, A Kawasaki. Physicochemical properties of single phase $\mathrm{La}_{2} \mathrm{Zr}_{2} \mathrm{O}_{7}$ particle. Materials Transactions 2005; 46: 189-192.

[19] KK Rao, T Banu, M Vithal, et al. Preparation and characterization of bulk and nanoparticles of $\mathrm{La}_{2} \mathrm{Zr}_{2} \mathrm{O}_{7}$ and $\mathrm{Nd}_{2} \mathrm{Zr}_{2} \mathrm{O}_{7}$ by sol-gel method. Materials Letters 2002; 54: 205-210.
[20] NA Dhas, KC Patil. Combustion synthesis and properties of fine-particle rare-earth-metal zirconates, $\mathrm{Ln}_{2} \mathrm{Zr}_{2} \mathrm{O}_{7}$. Journal of Materials Chemistry 1993; 3: 1289-1294.

[21] S Komarneni. Hydrothermal preparation of the low-expansion NZP family of materials. International Journal of High Technology Ceramics 1988; 4: 31-39.

[22] JA Labrincha, JR Frade, FMB Marques. $\mathrm{La}_{2} \mathrm{Zr}_{2} \mathrm{O}_{7}$ formed at ceramic electrode/YSZ contacts. Journal of materials science 1993; 28: 3809-3815.

[23] S Wang, Y Zhai, X Li, et al. Co-precipitation synthesis of $\mathrm{MgO}$-doped $\mathrm{ZrO}_{2}$ nano powder. Journal of the American Ceramic Society 2006; 89: 3577-3581.

[24] MJ Readey, RR Lee, JW Halloran, et al. Processing and sintering of ultrafine $\mathrm{MgO}-\mathrm{ZrO}_{2}$ and $\left(\mathrm{MgO}, \mathrm{Y}_{2} \mathrm{O}_{3}\right)-\mathrm{ZrO}_{2}$ Powders. Journal of the American Ceramic Society 2010; 73: 1499-1503.

[25] H Guo, X Yang, T Xiao, et al. Structure and optical properties of sol-gel derived $\mathrm{Gd}_{2} \mathrm{O}_{3}$ waveguide films. Applied Surface Science 2004; 230: 215-221.

[26] S Xing, G Zhao. Morphology and thermostability of polypyrrole prepared from SDBS aqueous solution. Polymer Bulletin 2006; 57: 933-943.

[27] C Wang, Y Wang, L Wang, et al. Hydrothermal assisted synthesis and hot-corrosion resistance of nano lanthanum zirconate particles. Ceramics International 2014; 40: 3981-3988.

[28] MS Kaliszewski, AH Heuer. Alcohol interaction with zirconia powders, Journal of the American Ceramic Society 2010; 73: 1504-1509.

[29] X Cheng, X Zhang, H Yin, et al. Modifier effects on chemical reduction synthesis of nanostructured copper, Applied Surface Science 2006; 253: 2727-2732.

[30] CS Smith. Grains, phases, and interphases: an interpretation of microstructure. Metals Technology 1948; 175: 15-51.

[31] JE Burke. Some factors affecting the rate of grain growth in metals. Transactions of the American Institute of Mining and Metallurgical Engineers 1949; 180: 73-91.

[32] JE Burke, D. Turnbull. Recrystallization and grain growth. Progress in Metal Physics 1952;3: 220-292.

[33] S Shukla, S Seal, R Vij, et al. Reduced activation energy for grain growth in nanocrystalline yttria-stabilized zirconia, Nano Letters 2003;3: 397-401. 